\title{
Increased urinary adiponectin level is associated with contrast-induced nephropathy in patients undergoing elective percutaneous coronary intervention
}

\author{
Jun-yi Zhang ${ }^{\dagger}$, Qiong Wang ${ }^{\dagger}$, Ru-tao Wang, Fei Li, He-xiang Cheng, Kun Lian, Yi Liu and Ling Tao*io
}

\begin{abstract}
Background: Contrast-induced nephropathy $(\mathrm{CIN})$ is one of major and serious complications in patients undergoing percutaneous coronary intervention (PCI). It is unknown whether increased urinary adiponectin (UAPN), a sensitive marker for early renal function impairment, is associated with an increased risk of CIN. Therefore, we prospectively investigate the association of UAPN with CIN.

Methods: We prospectively enrolled 208 patients who were undergoing elective PCI. The baseline UAPN was assessed prior to $\mathrm{PCl}$. The ROC analysis was used to evaluate the predictive value of UAPN for CIN. Multivariate logistic regression analysis was performed to analyze the independent risk factors for CIN.

Results: Of 208 patients, CIN occurred in 19 patients (9.13\%), and 6 of them (2.88\%) required dialysis. Patients with CIN had a higher UAPN level than those without CIN $(17.15 \pm 12.36$ vs. $10.29 \pm 3.04 \mathrm{ng} / \mathrm{ml}, P<0.01)$. ROC analysis showed that the optimal cutoff value of UAPN for predicting CIN was $12.24 \mathrm{ng} / \mathrm{ml}$ with $68.42 \%$ sensitivity and $76.72 \%$ specificity (AUC $=0.7204 ; 95 \% \mathrm{Cl}, 0.582-0.859 ; \quad<0.01)$. Multivariate analysis demonstrated that UAPN (OR, 5.071; 95\% Cl,1.711-15.028; $P<0.01)$ and serum creatinine $(\mathrm{Scr})>124 \mu \mathrm{mol} / \mathrm{L}(\mathrm{OR}, 4.210 ; 95 \% \mathrm{Cl}, 1.297-13.669 ; P<$ 0.01 ) were independently associated with CIN.
\end{abstract}

Conclusions: Our present study showed that a higher baseline UAPN ( $\geq 12.24 \mathrm{ng} / \mathrm{ml})$ level was significantly associated with an increased risk for developing CIN post PCl.

Keywords: Percutaneous coronary intervention, Urinary adiponectin, Contrast-induced nephropathy

\section{Background}

Contrast-induced nephropathy (CIN) is a frequent and serious complications in patients who undergo percutaneous coronary intervention (PCI), accounting for $12 \%$ hospital-acquired acute kidney injury [1]. CIN increases risk of dialysis and in-hospital mortality in patient undergoing PCI [2]. CIN is defined as "an absolute $(\geq 0.5$ $\mathrm{mg} / \mathrm{dl}$ ) or relative increase $(\geq 25 \%)$ in serum creatinine (Scr) at $48-72 \mathrm{~h}$ after exposure to a contrast agent

\footnotetext{
* Correspondence: liuyimeishan@hotmail.com; lingtao@fmmu.edu.cn

† Jun-yi Zhang and Qiong Wang contributed equally to this work.

Department of Cardiology, Xijing Hospital, Fourth Military Medical University,

15 Changle West Road, Xi'an 710032, Shannxi, China
}

compared to baseline Scr values, when alternative explanations for renal impairment have been excluded" [3, 4]. Although Scr has been widely used to evaluate CIN, there are many criticisms on this biomarker, such as poor correlation to eGFR [5], and its failure to reflect early or slight changes in renal function [6]. Therefore, the search for more rapid and sensitive biomarkers in addition to traditional renal function assessment might help to identify the patients at increased risk for developing CIN.

The pathogenesis of CIN is uncertain and controversial. Endothelial dysfunction, distribution of renal blood flow and oxidative stress are considered to be possible 
pathophysiological mechanisms responsible for CIN [7]. Adiponectin, an adipocytokines, possesses potential antiinflammatory property on endothelial cells by alleviating vascular inflammation [8]. Experimental model demonstrates that adiponectin deficiency mice exhibits increased albuminuria and fusion of podocyte foot processes, and adiponectin supplementation reduces podocyte permeability to albumin and podocyte dysfunction by inhibition of AMPK-NADPH oxidase signaling, which indicates that adiponectin regulates albuminuria by modulating oxidant stress [9]. A recent clinical study demonstrates that the concentration of urinary adiponectin (UAPN) is significantly enhanced in diabetes [10]. The increased UAPN is also a strong independent predictor of diabetic nephropathy progression from macroalbuminuria to end-stage renal disease and is an even better predictor than albumin excretion rate or as good as estimated glomerular filtration rate [11]. Therefore, the UAPN may be a more rapid, reliable and sensitive predictor of vascular and kidney injury, and may precede the onset of increased Scr or albuminuria.

However, no relevant report is currently available regarding whether UAPN is associated with CIN after PCI. In the present study, we aimed to investigate the association of UAPN, a sensitive marker for early vascular and kidney injury, with CIN.

\section{Methods}

\section{Study population}

This observational study was performed at Xijing Hospital, China, from February 2011 to May 2012. Two hundred eight adult patients with coronary heart disease who agreed to receive elective PCI treatment were enrolled prospectively. The exclusion criteria included pregnancy, infectious or inflammatory diseases, end stage renal disease, severe left heart dysfunction (NYHA $\geq$ III or LVEF< $20 \%$ ), allergy to contrast agent, malignant tumor, severe hepatic dysfunction and previous myocardial infarction. The study was approved by ethics committee of Xijing Hospital, China.

\section{Study protocol and definition}

Baseline UAPN levels and Scr were tested $24 \mathrm{~h}$ before angiography. The midstream morning urine was collected and tested by Enzyme linked immunosorbent assay (ELISA). The UAPN value was measured as $\mathrm{ng} / \mathrm{ml}$. Regular Scr test during 48-72 h following PCI was performed to diagnose CIN. CIN is defined as "an absolute $(\geq 0.5 \mathrm{mg} / \mathrm{dl}$ ) or relative increase $(\geq 25 \%)$ in Scr at $48-72$ $\mathrm{h}$ after exposure to a contrast agent compared to baseline $\mathrm{Scr}$ values, when alternative explanations for renal impairment have been excluded" [12]. The estimated glomerular filtration rate (eGFR) was calculated by the Modification of Diet in Renal Disease (MDRD) formula, and eGFR $<60 \mathrm{ml} / \mathrm{min} / 1.73 \mathrm{~m}^{2}$ was defined as impaired renal function [13].

\section{Coronary interventions and medications}

PCI were performed according to present guideline [14]. The choice of contrast medium was left to the operator's discretion. After PCI, all patients received the dual antiplatelet therapy (DAPT) according to present guideline [14]. Use of other medications ( -receptor blockers, statin or angiotensin-converting enzyme inhibitor) was left to the discretion of individual cardiologist.

\section{Statistical analysis}

Data was analyzed using the Statistical Analysis System (SAS) version 9.4for Windows. Continuous variables were expressed as mean \pm SD and analyzed by Student's t-tests or Wilcoxon rank-sum test. The categorical variables were expressed as percentages and analyzed by chi-square test or Fisher's exact test. The receiver operating characteristics (ROC) curve was conducted to evaluate predictive value of UAPN for CIN and determine the cutoff value. The areas under the ROC curve (AUC) were calculated for each predictor as well. The statistical significance of differences after logistic regression between AUCs was also determined. Statistical analysis was conducted by logistic regression, analyzing diagnosis value of single and combined prediction of UAPN and Scr for CIN. Univariate and multivariate logistic regressions were used to identify the independent risk factors associated with CIN. In all tests, the differences were considered statistically significant at $P<0.05$.

\section{Results}

\section{Clinical characteristics}

Two hundred eight eligible patients were enrolled in the present study. 19 (9.13\%) of them developed CIN after undergoing $\mathrm{PCI}$ and $6(2.88 \%)$ required dialysis. But no CIN related death was identified. The baseline clinical characteristics were shown in Table 1 . The mean age was $61.34 \pm 9.87$ years, and $79.33 \%$ were male. $35.10 \%$ of patients had diabetes mellitus. Hypertension and dyslipidemia were observed in 64.90 and $44.71 \%$ of patients, respectively. Compared to non-CIN patients, Patients with CIN had a higher prevalence of diabetes $(57.90 \%$ vs. $32.80 \%, P=0.03)$. However, there were no significant differences between the two groups regarding the age, gender, BMI, smoking status, hypertension, dyslipidemia, medication therapies prior to PCI, left ventricular ejection fraction (LVEF), contrast material use and medications.

\section{Baseline laboratory characteristics}

The baseline laboratory characteristics were shown in Table 2. Patients with CIN had a higher baseline UAPN level $(17.15 \pm 12.36$ vs. $10.29 \pm 3.04 \mathrm{ng} / \mathrm{ml}, P<0.01)$, higher 
Table 1 Baseline clinical characteristics of the study patients with and without CIN

\begin{tabular}{|c|c|c|c|}
\hline Characteristics & $\begin{array}{l}\text { Patients without CIN } \\
(n=189)\end{array}$ & $\begin{array}{l}\text { Patients with CIN } \\
(n=19)\end{array}$ & $P$ value \\
\hline Age, y & $61.32 \pm 9.83$ & $61.53 \pm 910.51$ & 0.93 \\
\hline$\geq 70$ years n (\%) & $35(18.52 \%)$ & $5(26.32 \%)$ & 0.61 \\
\hline Male n (\%) & 149(78.84\%) & 16(84.21\%) & 0.80 \\
\hline hypertension n (\%) & $126(66.67 \%)$ & $9(47.37 \%)$ & 0.09 \\
\hline Diabetes mellitus n (\%) & $62(32.80 \%)$ & $11(57.90 \%)$ & 0.03 \\
\hline Dyslipidemia n (\%) & $85(44.97 \%)$ & $8(42.11 \%)$ & 0.81 \\
\hline Smoker n (\%) & $118(62.44 \%)$ & $8(42.11 \%)$ & 0.08 \\
\hline Waist-to-hip ratio & $0.97 \pm 0.04$ & $1.02 \pm 0.14$ & 0.27 \\
\hline 3-vessel CAD & $104(55.01 \%)$ & $14(73.68 \%)$ & 0.12 \\
\hline Contrast(ml) & $229.28 \pm 115.14$ & $295.79 \pm 169.91$ & 0.07 \\
\hline$\geq 300 \mathrm{ml} \mathrm{n} \mathrm{( \% )}$ & $41(21.69 \%)$ & $8(42.11 \%)$ & 0.09 \\
\hline LVEF (\%) & $53.13 \pm 8.85$ & $50.58 \pm 7.85$ & 0.07 \\
\hline$\leq 45 \% \mathrm{n}(\%)$ & $32(16.93 \%)$ & 7(36.84\%) & 0.06 \\
\hline \multicolumn{4}{|l|}{ Medications pre-PCl } \\
\hline ACEI/ARB n (\%) & $106(56.08 \%)$ & $8(42.11 \%)$ & 0.24 \\
\hline Statin n (\%) & $50(26.46 \%)$ & $4(21.05 \%)$ & 0.81 \\
\hline$\beta$-blocker n (\%) & $117(61.90 \%)$ & $8(42.11 \%)$ & 0.09 \\
\hline \multicolumn{4}{|l|}{ Medications post-PCl } \\
\hline Aspirin n (\%) & 189(100.00\%) & 19(100.00\%) & \\
\hline Clopidogrel n (\%) & 189(100.00\%) & 19(100.00\%) & \\
\hline Low molecular weight heparin $n(\%)$ & 189(100.00\%) & 19(100.00\%) & \\
\hline Statin n (\%) & 189(100.00\%) & 19(100.00\%) & \\
\hline ACEI/ARB n (\%) & 188(99.47\%) & 18(94.74\%) & 0.18 \\
\hline$\beta$-blocker n (\%) & 179(94.71\%) & 16(84.21\%) & 0.19 \\
\hline
\end{tabular}

Data are mean \pm standard deviation or number (\%). CAD Coronary heart disease, CIN Contrast-induced nephropathy, LVEF Left ventricular ejection fraction, ACEI Angiotensin-converting enzyme inhibitor, $A R B$ Angiotensin receptor blocker

Table 2 Baseline laboratory data of the study patients with and without CIN

\begin{tabular}{|c|c|c|c|}
\hline Characteristics & $\begin{array}{l}\text { Patients without CIN } \\
(n=189)\end{array}$ & $\begin{array}{l}\text { Patients with CIN } \\
(n=19)\end{array}$ & $P$ value \\
\hline$\overline{\mathrm{TC}}(\mathrm{mmol} / \mathrm{L})$ & $3.79 \pm 0.93$ & $3.82 \pm 0.88$ & 0.97 \\
\hline $\mathrm{TG}(\mathrm{mmol} / \mathrm{L})$ & $1.67 \pm 1.09$ & $1.51 \pm 0.82$ & 0.68 \\
\hline $\mathrm{HDL}(\mathrm{mmol} / \mathrm{L})$ & $0.95 \pm 0.29$ & $0.84 \pm 0.21$ & 0.19 \\
\hline $\mathrm{LDL}-\mathrm{C}(\mathrm{mmol} / \mathrm{L})$ & $2.35 \pm 0.84$ & $2.49 \pm 0.95$ & 0.75 \\
\hline $\mathrm{FBG}(\mathrm{mmol} / \mathrm{L})$ & $6.21 \pm 2.74$ & $8.06 \pm 2.72$ & $<0.01$ \\
\hline $\operatorname{Scr}(\mu \mathrm{mol} / L)$ & $88.82 \pm 21.13$ & $119.89 \pm 40.81$ & $<0.01$ \\
\hline$>124 \mathrm{umol} / \mathrm{L}$ & $13(6.88 \%)$ & $7(36.84 \%)$ & $<0.01$ \\
\hline $\mathrm{Hs}-\mathrm{CRP}(\mathrm{mg} / \mathrm{L})$ & $7.90 \pm 14.14$ & $15.42 \pm 13.99$ & $<0.01$ \\
\hline Urinary albumin ( $g / 24 \mathrm{~h})$ & $0.26 \pm 0.57$ & $0.47 \pm 0.82$ & 0.12 \\
\hline Hemoglobin ( $\mathrm{g} / \mathrm{L})$ & $134.24 \pm 16.22$ & $125.47 \pm 20.40$ & 0.087 \\
\hline UAPN (ng/ml) & $10.29 \pm 3.04$ & $17.15 \pm 12.36$ & $<0.01$ \\
\hline $\mathrm{eGFR}\left(\mathrm{ml} / \mathrm{min} / 1.73 \mathrm{~m}^{2}\right)$ & $64.14 \pm 16.55$ & $49.57 \pm 19.03$ & $<0.01$ \\
\hline$<60 \mathrm{ml} / \mathrm{min} / 1.73 \mathrm{~m}^{2} \mathrm{n}(\%)$ & $82(43.39 \%)$ & $14(73.68 \%)$ & 0.01 \\
\hline
\end{tabular}

Data are mean \pm standard deviation. TG Triglyceride, TC Total cholesterol, HDL High density lipoprotein, $L D L-C$ Low-density lipoprotein cholesterol, FBG Fasting blood-glucose, UAPN Urinary adiponectin, Scr Serum creatinine, Hs-CRP High-sensitivity C-reactive protein, eGFR Estimated glomerular filtration rate, CIN Contrast-induced nephropathy 
baseline fasting blood glucose(FBG)(8.06 \pm 2.72 vs. $6.21 \pm$ $2.74 \mathrm{mmol} / \mathrm{L}, P<0.01)$, higher Hs-CRP level $(15.42 \pm$ 13.99 vs. $\quad 7.90 \pm 14.14 \mathrm{mg} / \mathrm{L}, \quad P<0.01)$, lower eGFR $\left(49.57 \pm 19.03\right.$ vs. $\left.64.14 \pm 16.55 \mathrm{ml} / \mathrm{min} / 1.73 \mathrm{~m}^{2}, \quad P<0.01\right)$ than those without CIN. Additionally, the number of patients with eGFR $<60 \mathrm{ml} / \mathrm{min} / 1.73 \mathrm{~m}^{2}$ was significantly larger in CIN group $(73.68 \%$ vs. $43.39 \%, P=0.01$ ), and the number of patients with $\mathrm{Scr}>124 \mu \mathrm{mol} / \mathrm{L}$ was also significantly larger in $\mathrm{CIN}(36.84 \%$ vs. $6.88 \%, P<0.01)$ than those in non-CIN group.

\section{Role of UAPN on predicting CIN}

The ROC analysis was conducted to evaluate predictive value of UAPN for CIN and determine the optimal cutoff value of UAPN levels. As shown in Fig. 1, ROC analysis revealed that a UAPN cutoff value of 12.24 was optimal with 68.42\% sensitivity and $76.72 \%$ specificity for detecting CIN. The area under the curve (AUC) was 0.7204 (95\% CI, $0.582-0.859 ; P<0.01)$. Evidence exists that patients with a Scr level $>124 \mu \mathrm{mol} / \mathrm{l}$ have a high incidence of CIN [15]. In the present study, the cutoff value of UAPN $>12.24 \mathrm{ng} / \mathrm{ml}$ and $\mathrm{Scr}>124 \mu \mathrm{mol} / \mathrm{L}$ were used to compare their predictive value for CIN. As shown in Fig. 2 and Table 3, The AUC of UAPN $>12.24 \mathrm{ng} / \mathrm{ml}$, Scr $>124 \mu \mathrm{mol} / \mathrm{L}$ and UAPN $>12.24 \mathrm{ng} / \mathrm{ml}$ plus $\mathrm{Scr}>124 \mu \mathrm{mol} / \mathrm{L}$ were $0.7257(95 \% \mathrm{CI}$ : 0.614-0.837, $P<0.01$ ), 0.6498 (95\%CI: $0.537-0.763, P<$ $0.01)$ and $0.7509(95 \% \mathrm{CI}: 0.626-0.876 P<0.01)$, respectively. UAPN $>12.24 \mathrm{ng} / \mathrm{ml}$ and $\mathrm{Scr}>124 \mu \mathrm{mol} / \mathrm{L}$ had the same performance in predicting $\mathrm{CIN}$ than $\operatorname{Scr}(P=0.18)$, whereas adding UAPN to Scr could provide a better predictive value than $\operatorname{Scr}$ alone $(P=0.04)$.

Univariate and multivariate logistic regressions were used to identify the independent risk factors associated with CIN. As shown in Table 3, Univariate logistic regression found that diabetes mellitus, Scr $>124 \mu \mathrm{mol} / \mathrm{L}$ and UAPN $>12.24 \mathrm{ng} / \mathrm{ml}$ were associated with CIN (all $P<0.05)$. The contrast volume $>300 \mathrm{ml}$ and $\mathrm{Hs}-\mathrm{CRP}$ as common risk factor used in clinical practice were also included in the multivariate logistic regression analysis $[16,17]$. Multivariate analysis indicated that UAPN> 12.24um/ml (OR, 5.071; 95\% CI, 1.711-15.028; $P<0.01)$ and Scr > $124 \mu \mathrm{mol} / \mathrm{L}$ (OR, 4.210; 95\% CI, 1.297-13.669;

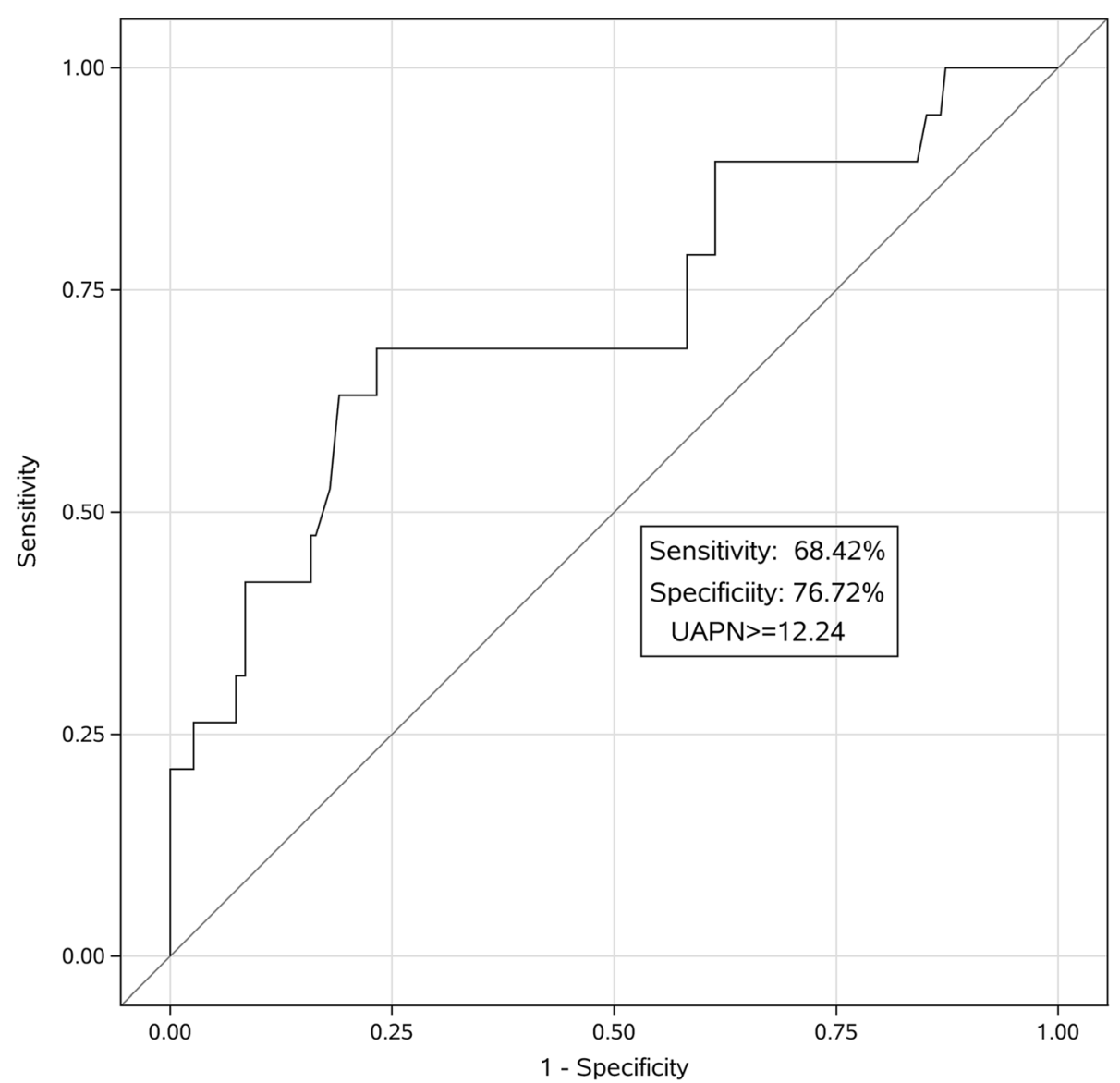

Fig. 1 ROC curve of UAPN. ROC curve analysis demonstrated that a UAPN cutoff value of 12.24 was optimal and exhibited $68.42 \%$ sensitivity and $76.72 \%$ for specificity detecting CIN. The C-statistic was 0.7204 ( $95 \% \mathrm{Cl}, 0.582-0.859 ; P<0.01)$. ROC $=$ receiver operator characteristic; UAPN $=$ urinary adiponectin; CIN = contrast-induced nephropathy 


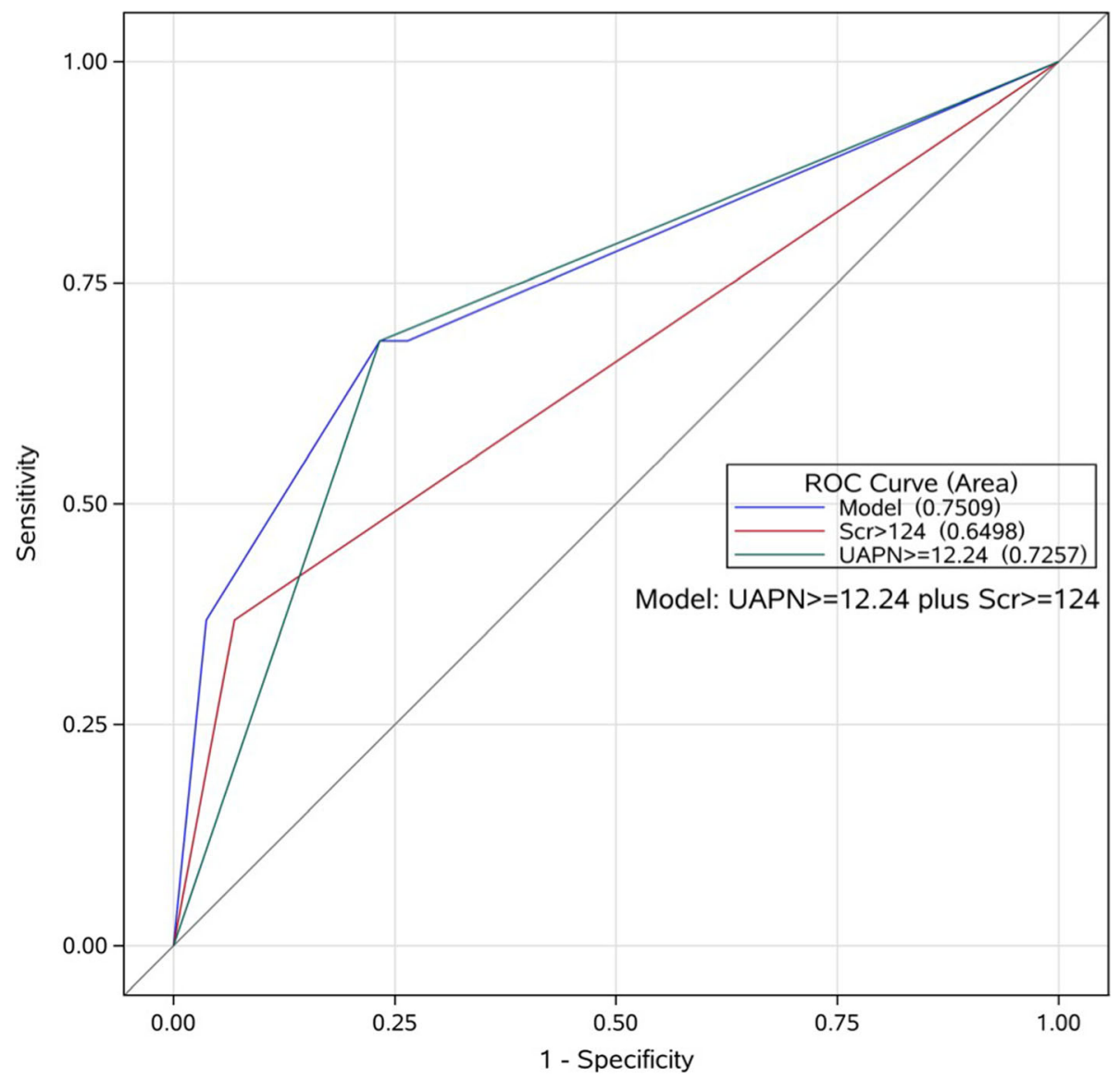

Fig. 2 ROC curves of APN $\geq 12.24$, Scr $\geq 124$ and APN $\geq 12.24$ plus $S c r \geq 124$ for predicting CIN. AUC of UAPN > 12.24 $\mu$ mol/L was 0.726 (95\%Cl: 0.614-0.837,

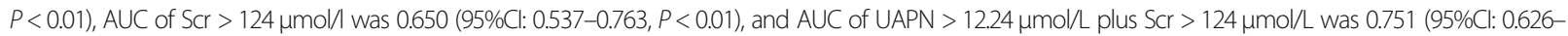
$0.876 P<0.01)$. ROC = receiver operator characteristic; $A U C=$ area under the curve; $U A P N=$ urinary adiponectin; $\mathrm{Scr}=$ serum creatinine; $\mathrm{Scr}=$ serum creatinine

$P<0.01)$ remained significant predictors for developing CIN in patients undergoing elective PCI (Table 4).

\section{Discussion}

In the present study, we investigated the predictive value of UAPN for the risk of CIN in patients undergoing PCI. For the first time, we demonstrated that patients with high baseline UAPN $(\geq 12.24 \mathrm{ng} / \mathrm{ml})$ are at a significantly higher risk for developing CIN post PCI. adding UAPN

Table 3 AUC of variables for predicting CIN

\begin{tabular}{llll}
\hline Variables & AUC & $95 \%$ Cl & $P$ value \\
\hline UAPN & 0.7204 & $0.582-0.859$ & $P<0.01$ \\
UAPN $\geq 12.24^{\text {a }}$ & 0.7257 & $0.614-0.837$ & $P<0.01$ \\
$\mathrm{~S} C r \geq 124$ & 0.6498 & $0.537-0.763$ & $P<0.01$ \\
UAPN $\geq 12.24$ plus Scr $\geq 124^{\text {b }}$ & 0.7509 & $0.626-0.876$ & $P<0.01$ \\
\hline
\end{tabular}

${ }^{a} U A P N \geq 12.24$ and $S c r \geq 124$ have the same performance in predicting $\mathrm{CIN}(P=0.18)$

${ }^{b}$ Adding UAPN $\geq 12.24$ to $S c r \geq 124$ could provide a better predictive value than $\mathrm{Scr} \geq 124$ alone $(P=0.04)$. AUC Area under the curve, UAPN Urinary adiponectin, Scr Serum creatinine, CIN Contrast-induced nephropathy to Scr could provide a better predictive value than $\mathrm{Scr}$ alone. In addition to traditional renal function assessment, UAPN levels, non-invasive biomarker, could be useful in selecting patients at increased risk CIN that requires closer monitoring post PCI.

It is reported that the prevalence of $\mathrm{CIN}$ in patients undergoing PCI ranged from 2 to 25\% [18].Patients who develop CIN after PCI have prolonged hospitalization, increased costs, increased rates of end-stage renal failure, myocardial infarction, repeat revascularization [19]. More importantly, patients who require dialysis after developing CIN have a $40 \%$ in-hospital mortality and $80 \%$ 2 -year mortality rates [20]. In the present study, $9 \%$ of patients developed CIN, which was consistent with previous reports [15]. 6(2.88\%) required dialysis. But no CIN related death was identified.

The pathophysiology of CIN is still controversial. Evidence exists that endothelial dysfunction and oxidative stress may be responsible for the $\operatorname{CIN}[7,21,22]$. The intervention strategy for treatment of CIN are limited and the pre-operative prevention is of most importance. 
Table 4 Univariate and multivariate logistic regression analyses for CIN

\begin{tabular}{|c|c|c|c|c|c|c|}
\hline \multirow[t]{2}{*}{ Risk Factor } & \multicolumn{3}{|c|}{ Univariate logistic regression } & \multicolumn{3}{|c|}{ Multivariate logistic regression } \\
\hline & $P$ value & OR & $95 \% \mathrm{Cl}$ & $P$ value & OR & $95 \% \mathrm{Cl}$ \\
\hline Diabetes Mellitus & 0.04 & 2.817 & $1.078-7.356$ & & & \\
\hline $\mathrm{Hs}-\mathrm{CRP}$ & 0.05 & 1.022 & $1.000-1.046$ & & & \\
\hline $\mathrm{Scr}>124 \mu \mathrm{mol} / \mathrm{L}$ & $<0.01$ & 7.897 & $2.658-23.469$ & $<0.01$ & 4.210 & $1.297-13.669$ \\
\hline Contrast volume $>300 \mathrm{ml}$ & 0.05 & 2.625 & $0.991-6.955$ & & & \\
\hline UAPN $>12.24 \mu \mathrm{m} / \mathrm{ml}$ & $<0.01$ & 7.140 & $2.563-19.890$ & 0.01 & 5.071 & $1.711-15.028$ \\
\hline
\end{tabular}

Multiple logistic regression model was conducted using stepwise method. Scr Serum creatinine, Hs-CRP High-sensitivity C-reactive protein, UAPN Urinary adiponectin

Therefore, it is important to identify high-risk patients who are susceptible to CIN before PCI. Although Scr has been widely used to evaluate $\mathrm{CIN}$, there are many criticisms on this biomarker, such as poor correlation to eGFR [5], and its failure to reflect early or slight changes in renal function [6]. Therefore, the search for more rapid, reliable, and sensitive biomarkers in addition to traditional renal function assessment might help to the diagnosis and screening of patients at high risk for developing CIN. Adiponectin, an adipocytokines, possess potential anti-inflammatory property on endothelial cells by alleviating vascular inflammation [23, 24]. Experimental model demonstrated that adiponectin deficiency mice exhibited increased albuminuria and fusion of podocyte foot processes, and adiponectin supplementation could reduce podocyte permeability to albumin and podocyte dysfunction by inhibition of AMPK-NADPH oxidase signaling, which indicates that adiponectin could regulate albuminuria by modulating oxidant stress [9]. Existing evidence also demonstrates that the accumulation of adiponectin is significantly increased in the injured kidney, which prevents glomerular injury by inhibiting oxidative stress and inflammation [25]. A recent clinical study demonstrated that the concentration of urinary adiponectin (UAPN) is significantly enhanced in diabetes [10]. The increased UAPN is also a strong independent predictor of diabetic nephropathy progression from macro-albuminuria to end-stage renal disease and was an even better predictor than albumin excretion rate or as good as estimated glomerular filtration rate [11].Therefore, the increased UAPN may be a reliable and sensitive biomarker in addition to traditional renal function for predicting CIN. In the present study, we firstly reported that the patients with CIN post PCI had a significant increase of baseline UAPN level. Multivariate analysis confirmed that UAPN concentrations remained independently predictor of CIN after adjusted for diabetes mellitus, Scr, contrast use and hs-CRP. More importantly, adding UAPN to Scr could provide a better predictive value than $\mathrm{Scr}$ alone. Therefore, in addition to traditional renal function assessment, UAPN levels, a non-invasive biomarker, could be useful in selecting patients at increased risk $\mathrm{CIN}$ that requires closer monitoring post PCI.

Except for UAPN, our multivariate logistic regressions model showed that Scr $>124 \mathrm{umol} / \mathrm{L}$ is also an independent risk factor for CIN, which is consistent with previous study [15]. Existing evidence has demonstrated that old age, hypertension, diabetes mellitus, hs-CRP, eGFR $<60$ $\mathrm{ml} / \mathrm{min} / 1.73 \mathrm{~m}^{2}$, high contrast dose et al. [18] are also predictors for CIN in the patient undergoing PCI. In the present study, although we found that patients in CIN group had significantly higher baseline FBG, hs-CRP and lower eGFR than those in non-CIN group, we did not find the predictive value of above-mentioned predictors in multivariate logistic regressions model. This may be attributed to the differences of the study cohort and sample size.

\section{Limitation}

Our present study has some limitations. Firstly, this study is an observational study and conducted in a single center. Secondly, this study included a relatively small sample size. The predictive value of UAPN for CIN should be validated in a larger population. Thirdly, the UAPN level was measured only once at admission, without correction for potential variability in levels. Fourthly, previous studies have shown that the high molecular weight(HMW)APN is the main APN isoform, whereas the low molecular weight (LMW) isoform is also present in the urine of patients with diabetes $[10,11]$. But we were not able to measure the UAPN isoforms, which may be more predictive for CIN.

\section{Conclusion}

Our present study showed that a higher baseline UAPN $(\geq 12.24 \mathrm{ng} / \mathrm{ml})$ level was significantly associated with an increased risk for developing CIN post PCI. The combination of UAPN with Scr showed a better performance than Scr alone. As a novel and easy-to-obtain method, in addition to renal function assessment, measurement of UAPN may emerge for the clinical assessment of CIN in patients undergoing PCI. The predictive of UAPN for CIN need to be validated in a larger population. 


\section{Abbreviations}

APT: Dual anti-platelet therapy; AUC: Area under the curve; CIN: Contrastinduced nephropathy; LVEF: Left ventricular ejection fraction; PCl: Percutaneous coronary intervention; ROC: Receiver operating characteristic; UAPN: Urinary adiponectin

\section{Acknowledgements}

The abstract of this study was published in J Am Coll Cardiol as part of poster sessions of 2013 scientific session of American College of Cardiology: J Am Coll Cardiol 2013 March.; 61 (Supplement): E1174. We sincerely thank Dr. Yanbin Song, Yan Qu and Lu Sun (Department of Cardiology, Xijing Hospital Fourth Military Medical University) for their assistance in the preparation for 2013 conference abstract. We are appreciative of Dr. Fan Li (Department of Health Statistics, Fourth Military Medical University) for statistical analysis support

\section{Authors' contributions}

$L T$ and $Y L$ originated the concept of the manuscript and led the writing of the manuscript. JYZ, QW and KL contributed to acquisition of data; RTW, HXC and FL analyzed and interpreted the data and made the statistical analyses. All authors participated in drafting the article. All authors have read and approved the manuscript.

\section{Funding}

This work was financially supported by Program for National Science Funds of China (Grants No. 81070676, 81400201), which provided financial support for the collection, analysis, and interpretation of data.

\section{Availability of data and materials}

The datasets used and analyzed during the current study are available from the corresponding author on reasonable request.

\section{Ethics approval and consent to participate}

The study was approved by the Ethics Committee of the Xijing Hospital of Fourth Military Medical University. Written informed consent was obtained from each participant.

\section{Consent for publication}

Not applicable.

\section{Competing interests}

The authors declare that they have no competing interests.

Received: 30 April 2019 Accepted: 26 June 2019

Published online: 03 July 2019

\section{References}

1. Mehran R, Aymong ED, Nikolsky E, Lasic Z, lakovou I, Fahy M, Mintz GS, Lansky AJ, Moses JW, Stone GW, et al. A simple risk score for prediction of contrast-induced nephropathy after percutaneous coronary intervention: development and initial validation. J Am Coll Cardiol. 2004;44(7):1393-9.

2. Rihal CS, Textor SC, Grill DE, Berger PB, Ting HH, Best PJ, Singh M, Bell MR, Barsness GW, Mathew $V$, et al. Incidence and prognostic importance of acute renal failure after percutaneous coronary intervention. Circulation. 2002;105(19):2259-64.

3. Thomsen HS, Morcos SK, ESUR. ESUR guidelines on contrast media. Abdom Imaging. 2006;31(2):131-40.

4. Mehran R, Nikolsky E. Contrast-induced nephropathy: definition epidemiology, and patients at risk. Kidney Int Suppl. 2006;(100):S11-5.

5. Lu Z, Yin J, Zhang G, Wu R, Zhao Q, Wang N, Yan C, Wang F. Underestimated incidence of kidney disease in nonrenal outpatient. Ren Fail. 2017;39(1):328-32.

6. Lagos-Arevalo P, Palijan A, Vertullo L, Devarajan P, Bennett MR, Sabbisetti V, Bonventre JV, Ma Q, Gottesman RD, Zappitelli M. Cystatin C in acute kidney injury diagnosis: early biomarker or alternative to serum creatinine? Pediatr Nephrol. 2015;30(4):665-76

7. Golshahi J, Nasri H, Gharipour M. Contrast-induced nephropathy; a literature review. J Nephropathol. 2014;3(2):51-6.

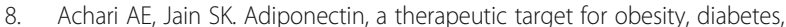
and endothelial dysfunction. Int J Mol Sci. 2017;18(6):E1321.
9. Sharma K, Ramachandrarao S, Qiu G, Usui HK, Zhu Y, Dunn SR, Ouedraogo R, Hough K, McCue P, Chan L, et al. Adiponectin regulates albuminuria and podocyte function in mice. J Clin Invest. 2008;118(5):1645-56.

10. von Eynatten M, Liu D, Hock C, Oikonomou D, Baumann M, Allolio B, Korosoglou G, Morcos M, Campean V, Amann K, et al. Urinary adiponectin excretion: a novel marker for vascular damage in type 2 diabetes. Diabetes. 2009;58(9):2093-9.

11. Panduru NM, Saraheimo M, Forsblom C, Thorn LM, Gordin D, Wadén J, Tolonen N, Bierhaus A, Humpert PM, Groop PH, et al. Urinary adiponectin is an independent predictor of progression to end-stage renal disease in patients with type 1 diabetes and diabetic nephropathy. Diabetes Care. 2015;38(5):883-90

12. Barrett BJ, Parfrey PS, Vavasour HM, McDonald J, Kent G, Hefferton D, O'Dea F, Stone E, Reddy R, McManamon PJ. Contrast nephropathy in patients with impaired renal function: high versus low osmolar media. Kidney Int. 1992; 41(5):1274-9.

13. Hafez T. Modification of diet in renal disease (MDRD) estimated glomerular filtration rate (eGFR) formula. Am J Cardiol. 2007;99(4):584.

14. Levine GN, Bates ER, Blankenship JC, Bailey SR, Bittl JA, Cercek B, Chambers CE, Ellis SG, Guyton RA, Hollenberg SM, et al. 2011 ACCF/AHA/SCAI guideline for percutaneous coronary intervention. A report of the American College of Cardiology Foundation/American Heart Association Task Force on practice guidelines and the Society for cardiovascular angiography and interventions. J Am Coll Cardiol. 2011:58(24):e44-122.

15. Calvin AD, Misra S, Pflueger A. Contrast-induced acute kidney injury and diabetic nephropathy. Nat Rev Nephrol. 2010;6(11):679-88.

16. Pandya B, Chalhoub JM, Parikh V, Gaddam S, Spagnola J, El-Sayegh S, Bogin M, Kandov R, Lafferty J, Bangalore S. Contrast media use in patients with chronic kidney disease undergoing coronary angiography: a systematic review and meta-analysis of randomized trials. Int J Cardiol. 2017;228:137-44.

17. Guo XS, Lin KY, Li HL, Chen JY, Zhou YL, Liu Y, Tan N, Atkins ER, Ran P, Yang $J Q$, et al. Preprocedural high-sensitivity C-reactive protein predicts contrastinduced nephropathy and long-term outcome after coronary angiography. Angiology. 2017;68(7):614-20.

18. Solomon R, Dauerman HL. Contrast-induced acute kidney injury. Circulation. 2010;122(23):2451-5

19. Fähling $M$, Seeliger $E$, Patzak A, Persson PB. Understanding and preventing contrast-induced acute kidney injury. Nat Rev Nephrol. 2017;13(3):169-80.

20. Dangas G, lakovou I, Nikolsky E, Aymong ED, Mintz GS, Kipshidze NN, Lansky AJ, Moussa I, Stone GW, Moses JW, et al. Contrast-induced nephropathy after percutaneous coronary interventions in relation to chronic kidney disease and hemodynamic variables. Am J Cardiol. 2005:95(1):13-9.

21. Seeliger E, Sendeski M, Rihal CS, Persson PB. Contrast-induced kidney injury: mechanisms, risk factors, and prevention. Eur Heart J. 2012;33(16):2007-15.

22. Wong PC, Li Z, Guo J, Zhang A. Pathophysiology of contrast-induced nephropathy. Int J Cardiol. 2012;158(2):186-92.

23. Lau WB, Tao L, Wang Y, Li R, Ma XL. Systemic adiponectin malfunction as a risk factor for cardiovascular disease. Antioxid Redox Signal. 2011;15(7):1863-73.

24. Cao Y, Tao L, Yuan Y, Jiao X, Lau WB, Wang Y, Christopher T, Lopez B, Chan L, Goldstein B, et al. Endothelial dysfunction in adiponectin deficiency and its mechanisms involved. J Mol Cell Cardiol. 2009:46(3):413-9.

25. Ohashi K, Iwatani H, Kihara S, Nakagawa Y, Komura N, Fujita K, Maeda N, Nishida M, Katsube F, Shimomura I, et al. Exacerbation of albuminuria and renal fibrosis in subtotal renal ablation model of adiponectin-knockout mice. Arterioscler Thromb Vasc Biol. 2007;27(9):1910-7.

\section{Publisher's Note}

Springer Nature remains neutral with regard to jurisdictional claims in published maps and institutional affiliations. 